\title{
Inclusive Education: Implementation of a Mobile Application for Blind Students
}

\author{
Alejandro Boza-Chua, Karen Gabriel-Gonzales, Laberiano Andrade-Arenas \\ Facultad de Ciencias e Ingeniería \\ Universidad de Ciencias y Humanidades \\ Lima, Perú
}

\begin{abstract}
Currently, the world is going through an era of changes in the education sector, but most Latin American countries are lagging, especially Peru, which does not have the technological tools that allow it to advance to an adequate level of inclusion of disabled students, especially blind students who are $60 \%$ of students who drop out of school for lack of education that have be suitable for their need. Consequently, the present research work is originated which aims to develop a mobile application oriented to the benefit of inclusive education of blind students. Therefore, the agile scrum methodology was used for the development of this project, executed in 5 phases, the requirements identified for the development of the mobile application were obtained through a questionnaire to 25 parents of visually impaired students, allowing the development of a mobile application that meets quality of inclusive education that can be applied in the education sector. Finally, as a result of the research work, another satisfaction survey was conducted with 50 parents where the application was evaluated, obtaining $90 \%$ of acceptance and satisfaction.
\end{abstract}

Keywords-Blind; disability; educational inclusion; mobile application; scrum methodology

\section{INTRODUCTION}

Over the last 20 years, the community's thinking and prioritization of the integration of the blind into the educational environment has undergone an incremental change that transformed the school environment and the pedagogical regime. For this reason, it has become one of the most important issues in the world, both in its educational organization and in the way of learning in the classroom [1]. Although two decades have passed since the revolutionary educational principle on the incorporation of blind students, not all countries have adapted to this, especially a large part of all Latin American countries.

Currently, Peru has great lack of technology oriented to blind students, being one of the main countries with a low percentage of educational inclusion. Likewise, the support and help provided by public services are really excessive. For this reason, $66 \%$ of students drop out of their academic studies [2]. The main reason is due to the scarcity of educational tools and the training that teachers receive, oriented to blind people. In such a way that the National Institute of Statistics and Informatics revealed the existence of more than 500 thousand students with visual impairment in Peru. However, although they are a large community, the public entity does not establish technology capable of meeting the primary needs of blind students. In the same way, with the training that should be provided to teachers for a better learning environment and development for blind students in order to provide integrated and inclusive education.

The existence of Law No. 29973 in Peru protects the community of people with disabilities. This article establishes that all people with disabilities have the right to obtain an adequate and quality educational development. However, although this law exists, it is not fully complied with, causing a corresponding educational deviation towards blind students. As a result, students are forced to accept precarious education without vision, being at a disadvantage by not receiving an adequate and favorable level of education for their professional growth [3].

Blind students who do not get appropriate educational support, delay the course of classes for other students. At other times, these blind students have little educational growth as they receive lesser assignments compared to their sighted peers, which is an obstruction to their learning. For this reason, these students fail the course or have low grades so that they remain at a lower level compared to other students [4]. Likewise, even if they are studying in the same grade, in the same cycle or in higher levels, it is evident the exclusion towards them within the activities developed in a classroom. This causes them to suffer and suffer within the educational environment [5]. It is therefore necessary that this issue emphasizes how important it is to establish a comprehensive system that supports blind students and guides teachers on proper training in the relationship with students. Above all because teachers are an essential part of educational development and advancement. In the same way, they have the function of carrying out an adequate search for measures that establish an inclusive environment using didactic strategies in the course of the development of their class [6], with the objective of promoting inclusion among sighted and blind students in order to reduce the educational limitations for students with visual impairment by including them.

Therefore, it is essential to establish viable planning for the educational growth of students with blindness, to provide a better inclusive education along with the development of technologies that support adequate professional growth. That is why this research work focuses on the implementation of a mobile application that benefits and promotes educational inclusion for blind students, to improve and promote the educational social environment.

The present research work is established by different sections. Section II shows the literature review. Likewise, as 
Section III, the methodological phase oriented to the development of the project is determined. On the other hand, Section IV shows the results of the research work oriented to the established methodology, in Section V the discussion. Finally, the last part is Section VI, which is defined by the conclusion and future work.

\section{REVIEW OF THE LiteratURE}

This study is based on the creation of a mobile application to promote educational inclusion for students with visual impairment, with the purpose of improving the quality of teaching. In this way, a feedback study was carried out, referring to the projects that provide benefits with better perspective. The author [7], affirms that one of the most valuable senses is sight since it allows the development of teaching towards the student. Also, the school is a general environment of visual stimuli, so that impedes the development of learning for blind people. Because it produces a demand for the requirement of technological tools to meet the needs of students.

For this reason, the author covered his research with the intention of developing a suitable mobile application to organize and recognize Cartesian coordinates by means of the convolutional neural system, supported by the advancement of the technological crack with validation and modeling of a set of neural networks. In order to develop this study, it was possible to use our own methodology which is divided into 4 phases, application, data development, choice of the appropriate neural architecture and, as the last phase, we have the training.

The results showed that, in order to achieve the general objective of the research work, it is essential to include a portion of data which compresses the images in order to be able to run a group of images originated from the information sector generated. Then, it was analyzed and the selection of the best pattern to put into operation of software was carried out. Thus, it was possible to determine that the circle of visually impaired people has rights determined by law. But for many of the media, it is difficult to have an interaction with blind people and the environment around them.

On the other hand, the author [8], mentions the various applications of Artificial Intelligence (AI) managed to obtain a great effect in a positive way in the various areas within an educational institution such as instruction and learning. For this study, a qualitative research analysis methodology was used. Thus, the results showed that this technology was able to improve the efficiency and effectiveness in the training of students. As conclusions, it was demonstrated that with the help of this technology it was possible to contribute to the development of student learning in their educational centers.

Also, the author [9], mentions that mobile applications provide many advantages in learning, which have been one of the most valuable tools for the performance of students and teachers in an academic way. The study is oriented in the design of an application, which will be used to improve the learning acquired after the development of classes through an intuitive interface. In this way, it supports the development of learning. As a result, a technological tool was developed, capable of contributing to the use of technology in a way that helps in its educational development. From another perspective, the author [10], points out that the contributions of technological tools, have not been oriented entirely to the improvement of the educational sector, but more in a method of survival of people who have a disability, The study was carried out to design a mobile game, oriented to people with visual impairment, using haptic signals and vibrations, obtaining as results that this game showed that the game is very useful for people with visual impairment and that it has been designed for people with visual impairment. Obtaining as results that this game showed to be suitable to improve confidence, satisfaction and happiness of life.

During the last few years, issues related to visual impairment have been one of the most researched topics worldwide. According to the author [11], this has led to an increase in studies on the development of tools that provide improvements for the visually impaired community. This work focuses on creating a mobile application for children between 6 and 14 years old who suffer from visual impairment, with the aim of helping in the development of learning. The results generated by this study are that it is possible to determine which models are ideal through object recognition.

In conclusion, the various authors were able to contribute on how the implementation of technological tools has improved and can improve the effectiveness and efficiency in educational centers. However, a good inclusion of students with disabilities has not been achieved; therefore, it can be mentioned that apps with various categories would play a very important role in the lifestyle of these people; improving the emotional and educational state. This reason is that it generates the beginning of our research.

\section{Methodology}

\section{A. Scrum Methodology}

For the development and implementation of this research work, the Scrum methodology was selected, this methodology is positioned among the best methodologies known worldwide, it is focused on software development, this methodology offers a suitable way to comply with good practices, before collaborative work giving the possibility of giving the best results in the projects, providing security and viability towards its final goal. On the other hand, the main characteristics of this methodology are based on its speed, adaptability, efficiency and flexibility [12]. It also has the guarantee of obtaining an environment, with security and transparency, having an environment of continuous progress, without loss of resources as it is a methodology prepared to change regardless of its difficulty [13].

The Scrum methodology consists of 5 production stages, as shown in Fig.1. The initiation stage focuses on examining, determining and investigating the requirements of the project. These requirements can be obtained through user surveys or meetings with the customer. The second stage is the implementation stage, which focuses on creating, estimating and identifying the user stories (HU) that were previously collected as requirements. Also, after that, the Sprint is determined, which is the time in which the project deliverables will be developed and, finally, the product backlog is created [12].

After performing the first two stages of the Scrum methodology, phase 3 follows, which is the implementation. The 


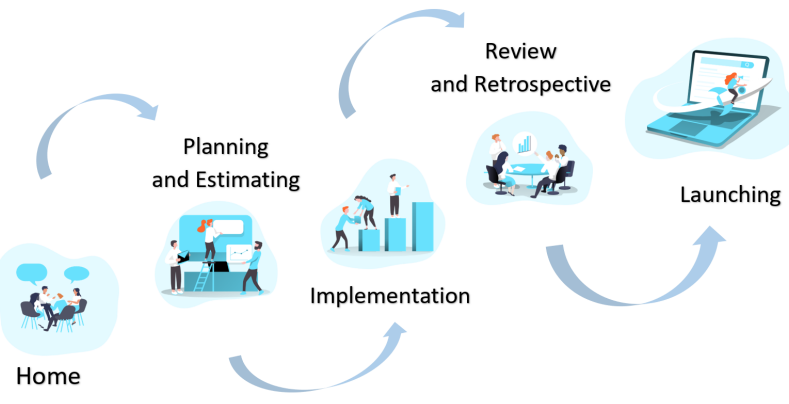

Fig. 1. Scrum Methodology Stages.

purpose of this stage is to develop the project deliverables at the Sprint level, complying with the corresponding user stories. Then follows the phase of review and retrospective of the entire project. This retrospective stage aims to perform inspections and verification that qualify the course of the project, proposing new commitments, solutions and constructive conclusions. On the other hand, the purpose of the review is to validate the development of the project, complying with the needs and user stories. Finally, the last stage of this methodology is the launching of the final delivery of the project [13].

1) Scrum Roles: This method contains 7 roles as shown in Table I, 3 of them are known as core Scrum roles, and the other 4 are known as non-core roles. On the one hand, the core roles are responsible for achieving the goals established for the project, thus being fundamental and mandatory for the performance of the execution, according to the Scrum methodology. While on the other hand, the non-core roles are not so necessary and important within the development of the project because the project can continue without their participation.

TABLE I. SCRUM ROLES

\begin{tabular}{l|l} 
Central Roles & Non-Central Roles \\
\hline Scrum Team & Users \\
\hline Scrum Master & Sponsor \\
\hline Product Owner & Stakeholder \\
\hline & Customer \\
\hline
\end{tabular}

The Scrum core team is composed of the central roles as shown in Table I, [14]. The first central role is the Scrum Master, who has the purpose of guiding, facilitating and providing good practices to the development team and verifying that everything goes according to plan. The second role is the Product Owner, who has the functionality of maximizing the project deliverables as well as receiving and transmitting the needs or requirements from the customer. Finally, the third role is the Scrum Team, which has the functionality to generate the project deliverables referring to the requirements specified at the level of the business method transmitted through the Product Owner [15].

\section{B. Methodology Development}

1) Home: The first phase of the scrum methodology in this research work was established in the realization of a questionnaire directed to 25 parents of blind students from different educational centres in Peru to collect requirements that allow to know the main requirements that need to be satisfied for viable education oriented to blind students. After having carried out the questionnaire through the results obtained, the user stories were established, which are shown in Table II. On some occasions within this research, HU-"number" will be placed referring to the user stories and the number to which they belong or simply HU referring to the user stories.

\section{TABLE II. USER STORIES}

\begin{tabular}{l|l}
$\mathbf{N}^{\circ}$ & Definition \\
\hline HU-01 & $\begin{array}{l}\text { As the administrator, I want the application to have a voice guide so } \\
\text { that the blind student can interact with the functions of the mobile } \\
\text { application. }\end{array}$ \\
\hline HU-02 & $\begin{array}{l}\text { I as an administrator want the mobile application to have the option to } \\
\text { provide voice assistant gender selection for the student to get a better } \\
\text { convenience and experience within their learning. }\end{array}$ \\
\hline HU-03 & $\begin{array}{l}\text { As an administrator, I want the mobile application to have the function } \\
\text { of being able to select different subjects for the student to choose } \\
\text { according to his or her predilection. }\end{array}$ \\
\hline HU-04 & $\begin{array}{l}\text { As a student, I want the mobile application to have the division of the } \\
\text { courses by subject so that I can choose according to what I want to } \\
\text { study. }\end{array}$ \\
\hline HU-05 & $\begin{array}{l}\text { As the administrator, I want the mobile application to be divided } \\
\text { according to the educational level so that the subjects are directed } \\
\text { to the student according to his rank and he can select according to his } \\
\text { preference. }\end{array}$ \\
\hline HU-10 & $\begin{array}{l}\text { As the administrator, I want the application to provide a report on } \\
\text { the student's progress within the application so that the supervisor or } \\
\text { the student knows about his or her progress with respect to the topics } \\
\text { within each course. }\end{array}$ \\
\hline HU-07 & $\begin{array}{l}\text { As the administrator, I want the mobile application to have motiva- } \\
\text { tional alerts so that when the student finishes each exercise, he/she } \\
\text { feels encouraged to continue learning. }\end{array}$ \\
\hline HU-08 & $\begin{array}{l}\text { As the administrator, I want the mobile application to have two ways } \\
\text { of taking the exams, a graded exam so that the student can know the } \\
\text { level of his knowledge and another exam without grading so that the } \\
\text { student can practice. } \\
\text { interaction functions within all the questions in the exam, both } \\
\text { questions and answers, so that the blind student has the possibility } \\
\text { to develop and interact with the application satisfactorily. }\end{array}$ \\
\hline his or her preference.
\end{tabular}

2) Planning and Estimating: After identifying the user stories through the requirements, the next process was to analyze each of the user stories in the planning and estimation stage. In this phase the product backlog was developed in which the user stories were estimated and prioritized and the type of origin and sprint they belong to were defined. For the estimation process, the planning poker mechanism was used. This is a strategy that allows a vote by the scrum team, they give a number to each user story, according to how much they believe that the development of the user story will require time and resources, testing the experience of each of the members of the scrum team.

The next process in this stage was the prioritization, where the importance of the development of a user story within the project is rated according to its importance, following an ascending order for its creation. After having both data, prioritization and estimation, the backlog is created, which contains both data, plus three aggregate columns. The first aggregate column is the status of the user story, the status can be pending (PE), in process (PR) and finished (FI). As the second column added, the type of origin of the user story is placed, qualifying according to what it generates. Finally, there 
is a column of the sprint number corresponding to each user story, all of this can be visualized in Table III.

\section{TABLE III. PRODUCT BACKLOG}

\begin{tabular}{l|l|l|l|l|l}
$\mathbf{N}^{\circ}$ HU & Estimate & Prioritization & Status & Origin & Sprint \\
\hline HU-01 & 8 & 1 & PE & Service & 3 \\
\hline HU-02 & 5 & 2 & PE & Service & 3 \\
\hline HU-03 & 3 & 3 & PE & Service & 2 \\
\hline HU-04 & 3 & 4 & PE & Service & 2 \\
\hline HU-05 & 5 & 5 & PE & Service & 3 \\
\hline HU-06 & 5 & 6 & PE & Report & 2 \\
\hline HU-07 & 1 & 10 & PE & Service & 1 \\
\hline HU-08 & 8 & 7 & PE & Service & 1 \\
\hline HU-09 & 5 & 8 & PE & Service & 2 \\
\hline HU-010 & 8 & 9 & PE & Service & 1 \\
\hline
\end{tabular}

After having performed the product backlog, the speed of each sprint is analyzed and defined; this depends on the experience of the scrum team. Likewise, for this process, the number of user stories to be performed in each sprint is selected according to the story points accumulated between them, which makes the story points equal to the speed per sprint. In addition, the most important thing for this process is that the prioritization is selected as a guide as shown in Fig. 2.

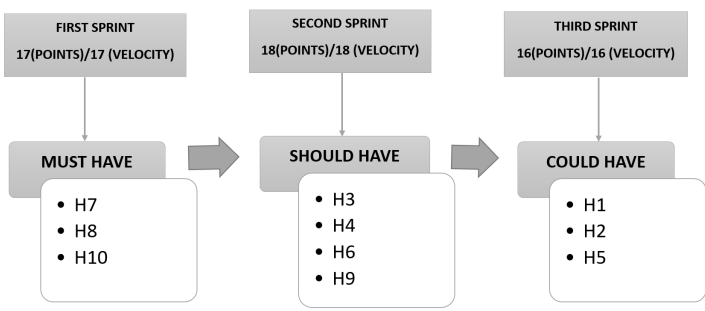

Fig. 2. Speed of Development.

3) Implementation: Through this stage of the Scrum method, the development of the requirements will be presented as user stories divided into three sprint, the user stories will be shown according to their corresponding sprint in order of execution.

- First Sprint: For this first stage of deliverables, the first sprint was given 17 user story points, which are equivalent to the speed this sprint will take. This iteration was divided between three user stories. As the first development of user stories for the first Sprint, user story number 8 was executed, as shown in Fig. 3(a), which has the purpose of providing the student with a choice between two ways to perform an exam. On the one hand, one will have the functionality of being able to develop it without having any qualification, thus giving an advantage to the student to be able to practise the topics he/she believes convenient. On the other hand, a test was created to evaluate the student's level in different topics, to evaluate how much the student has learned up to that moment. On the other hand, Fig.3 (b) shows the user story number 10 as the second deliverable of the first sprint, which has the purpose of implementing tests with a voice assistant to facilitate its development. This voice assistant will ask the questions, each of these questions contains four options set in buttons that contain audios with the answers, providing a simple use of the mobile application. Finally, as the last deliverable of the first sprint, the user story number 7, shown in Fig. 4(a), was defined. The purpose of this story is to generate motivational messages spoken by the voice assistant every time the student successfully completes each question in the exam.

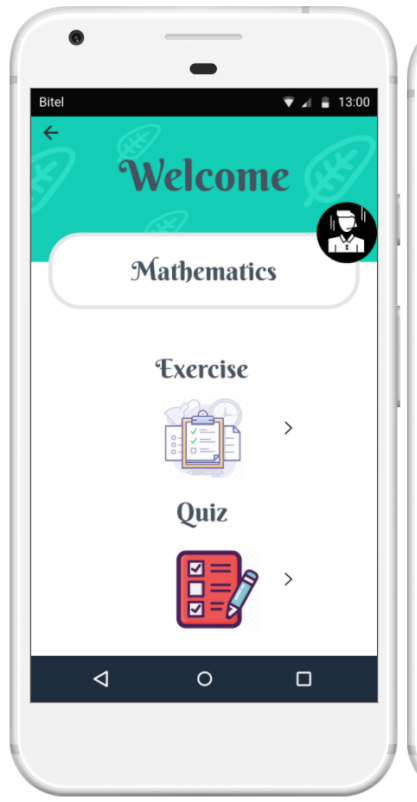

(a) $\mathrm{HU}-08$

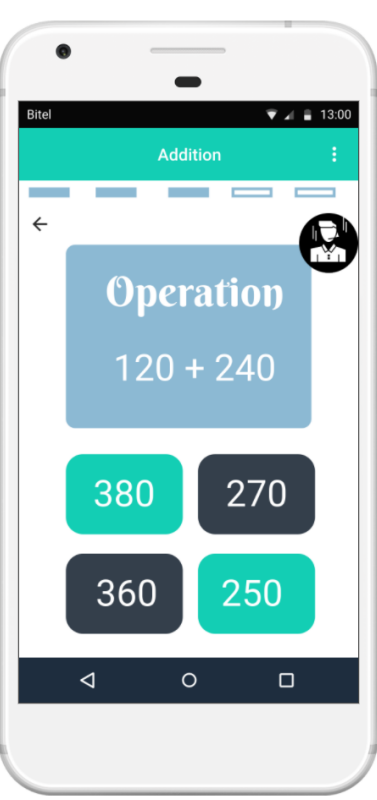

(b) HU-10
Fig. 3. First and Second Prototype.

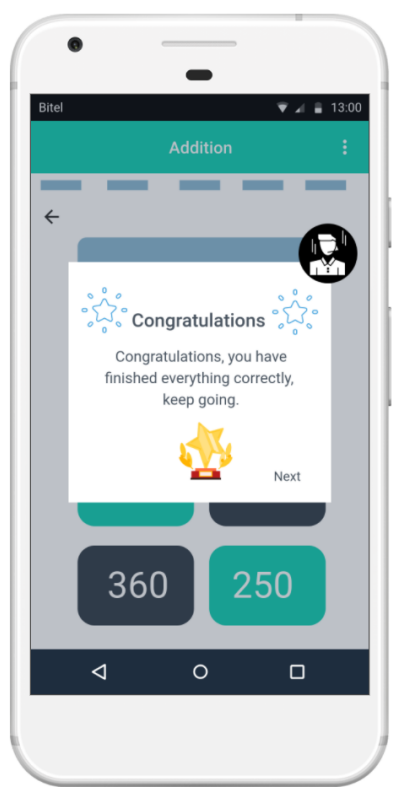

(a) $\mathrm{HU}-07$

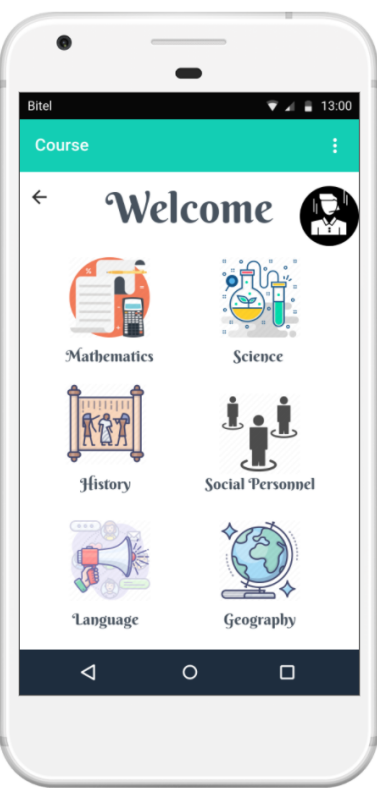

(b) HU-03
Fig. 4. Third and Fourth Prototypes. 
- Second Sprint: In the second deliverable stage, 18 story points equivalent to the speed of the current Sprint, which contains 4 user stories, were established and the first deliverable was based on user story number 3. Therefore, it is reflected in the requirement that requests the submission of several courses for the educational growth of the student. Also, this varies according to the educational level of the student, which provides different courses according to their rank, an example of this is shown in Fig. 4(b). As a second deliverable within the second Sprint, was developed the user story number 4 as shown in Fig. 5(a), which has the functionality to separate the course into several topics establishing a greater order for their interaction, where the relationship between the student and the voice assistant is implied.

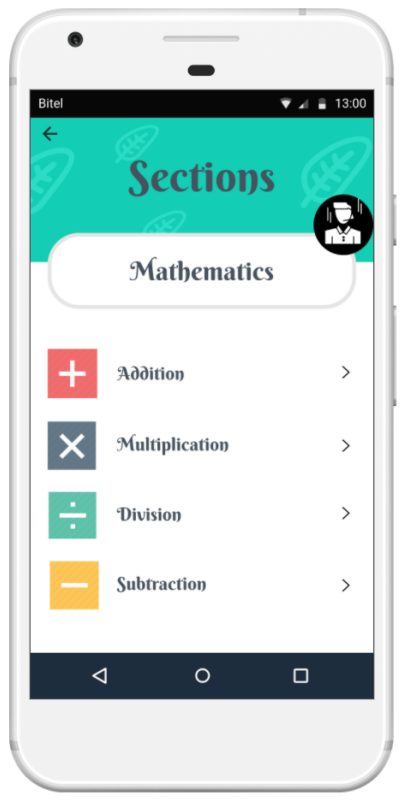

(a) HU-04

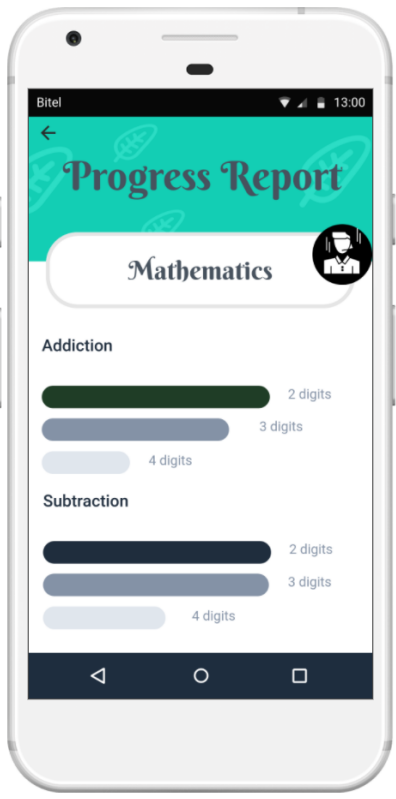

(b) HU-06
Fig. 5. Fifth and Sixth Prototypes.

On the other hand, the third deliverable of the second Sprint was developed based on the user story number 6 , which has the purpose of generating a report regarding the student's development in the application, with the objective of being able to know according to statistics their progressive progress in different courses, as shown in Fig. 5(b). As the last deliverable of the second Sprint, user story number 9 was developed. The purpose of which was to establish an environment that divides the exams according to levels of difficulty, levels such as easy, moderate, normal, and difficult, giving the student the freedom to select according to their preference, as can be seen in Fig. 6(a).

- Third Sprint: In the third stage of the deliverables, 16 users story points were established, which are equivalent to the speed of the present sprint made up of 3 user stories. The first deliverable of the third Sprint was based on the development of the user story number 1, which aims to generate the connection between the system and the student. Therefore, a voice assistant was developed to perform and interact with the student in different functions, part of this can be seen in Fig. 6(b), where it is visualized that since the application is opened, the voice assistant is turned on.

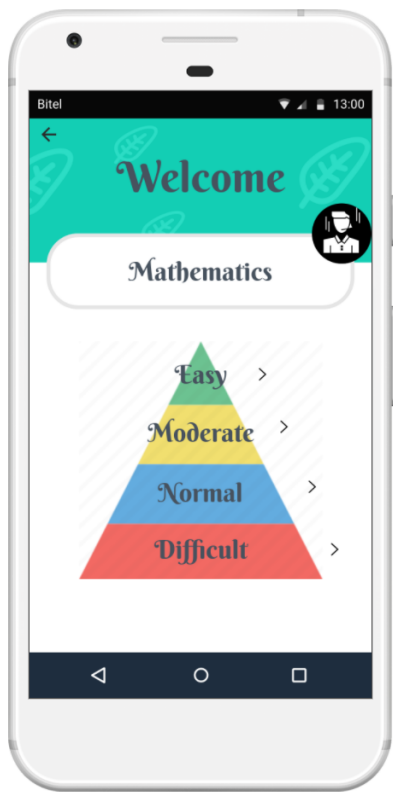

(a) HU-09

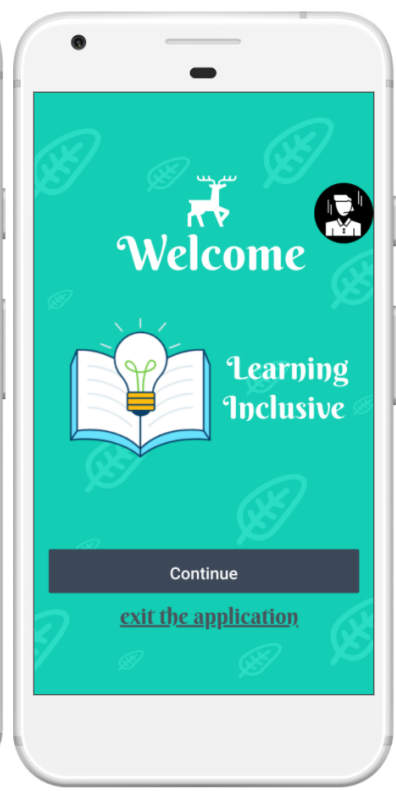

(b) HU-01
Fig. 6. Seventh and Eighth Prototypes.

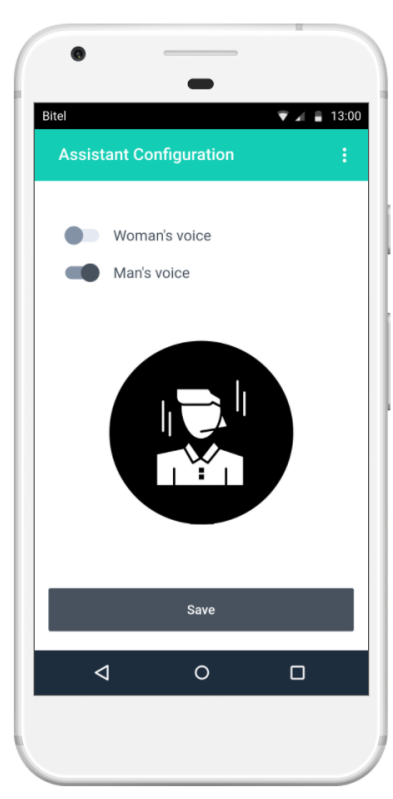

(a) HU-02

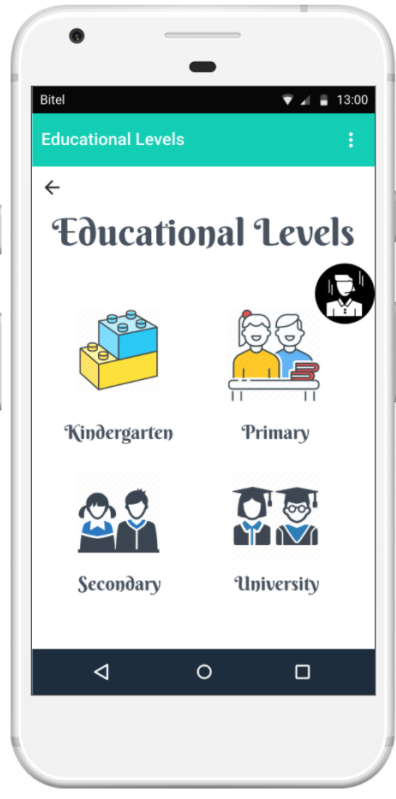

(b) HU-05
Fig. 7. Ninth and Tenth Prototypes.

As the second deliverable for this Sprint, user story number 2 was developed as shown in Fig. 7(a), this 
has the purpose of establishing comfort for the student through their auditory interaction with the voice assistant by being able to decide the gender of the assistant in order to improve their experience. Finally, as the last deliverable for the third Sprint, the user story number 5 was developed as shown in Fig. 7(b), this has the purpose of granting and generating ranks referring to the educational level of the student, levels such as kindergarten, elementary, high school and college level.

4) Review and Retrospective: On the review and retrospective process of the research work, oriented to the scrum methodology, an analysis divided into two parts was established both at the project execution level and at the level of requirements fulfillment converted into user stories. On the other hand, for this stage, an analysis has been made using three of the main scrum graphs, with the objective of knowing the feasibility of the development of this project. The first graph established was the speed diagram. This diagram checks the development at acceleration level on the execution and the course of each Sprint, as you can see in Fig. 8 where it was determined as axis $(\mathrm{X})$ the accumulation of points of user stories, also as axis (Y) was determined the number of sprints. On the other hand, through this diagram it was observed that the points established for each sprint according to the user stories were developed according to what was established.

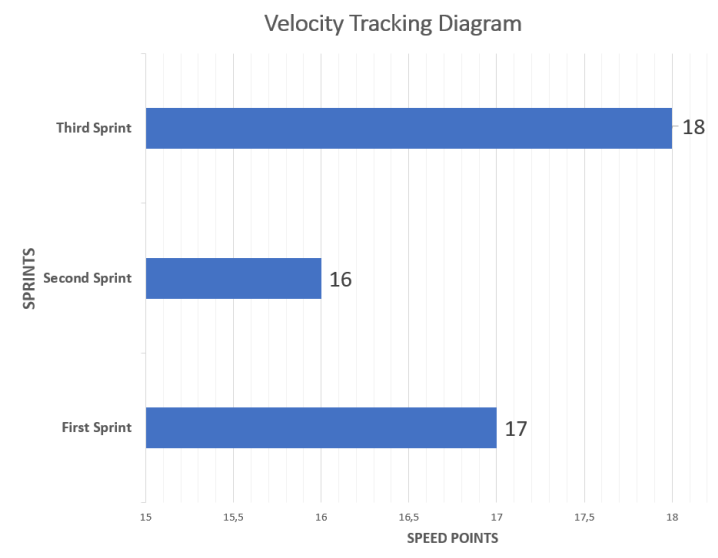

Fig. 8. Velocity Tracking Diagram.

The second graph shows the downward burned diagram, directed to the structural model on the story points and the ideal progress, where it was determined as axis $(\mathrm{X})$ the weeks of project development and as axis (Y) the story points, in the case of the story points it is started by the total of all the Sprint and subtracted by week according to the developed story points. The purpose of this diagram is to provide an analysis that relates the difference between an ideal time established and the real time obtained during the course of the project, as can be seen in Fig. 9. As a result of this, it was obtained that an adequate execution was not followed between week 1 and 3 due to the coupling of the team in different activities within the user stories deviating an ideal follow-up, after that the deviation was restored in week 4 allowing to conclude in the exact time that was predetermined in week 6 .

Finally, the downward burned diagram was developed,

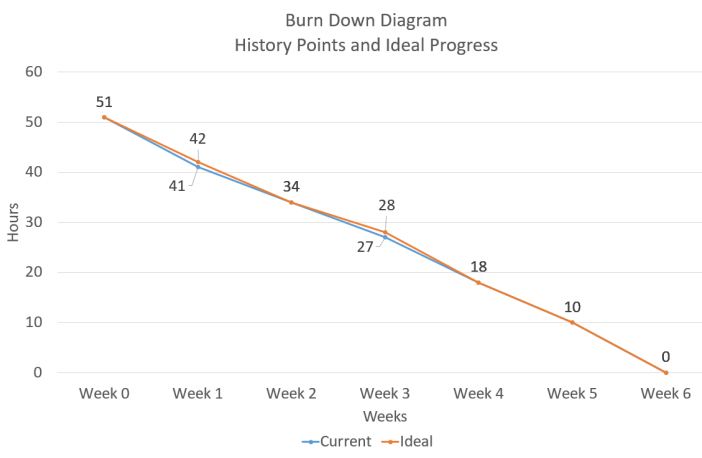

Fig. 9. Burn Down Scheme PI Method.

but unlike the previous one, the diagram is shown in Fig. 10 was oriented to the structural model on the remaining estimated effort. For this purpose, the weeks covered by the project development were determined as axis $(\mathrm{X})$ and the hours of project development in each Sprint were determined as axis (Y). In the case of hours, the first data was the total accumulation of hours covered by all the Sprint, then the hours that have been completed are subtracted per week. By means of this diagram, it was analyzed, and it was possible to deduce that the execution of the project was totally in accordance with the established by the fact that it agrees to the number of weeks with respect to the previous table and to what was analyzed in the second part of the methodology.

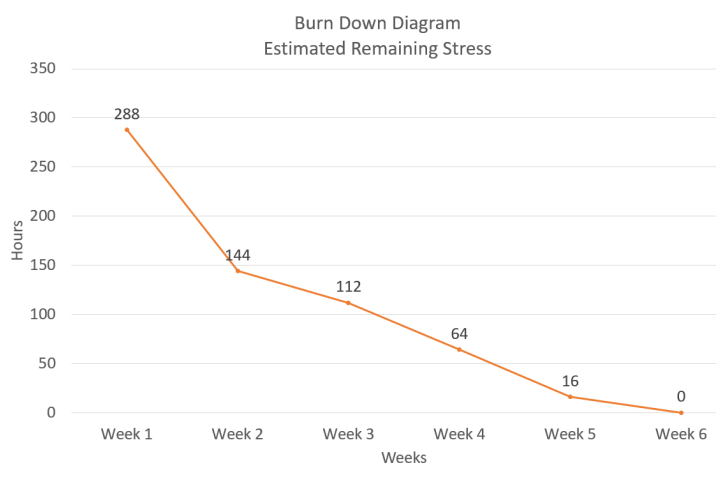

Fig. 10. Downward Burning Scheme EER Method.

\section{Development Tools}

1) Android Studio: This is a tool aimed at an embedded development environment for mobile application programming. In addition, it offers features that increase the production quality of mobile application development by providing a unified environment [16]. In addition, this development environment has the facility to generate suitable distribution, as well as to reuse code and resources for more agile development [17].

2) Java Programming Language: This programming language is one of the most recognized, provides the development and execution of various types of applications, highlighted by its structure and composition for programming, especially for mobile applications containing high adaptability, aimed at different mobile devices [18]. The main advantages are that it is a simple to understand language, object-oriented language, 
distributed applications, and, finally, the security it provides [19] [20].

3) Marvel App: This tool facilitates the production of prototypes for mobile applications and web pages. It also provides better usability compared to other prototyping tools as it has greater definition with a better navigation structure [21]. In addition, its main advantages are based on collaborative work and its adaptability to the prototyping of different types of devices, as well as to the variation of operating systems [22].

4) SQLite: It is one of the databases with open source code with greater recognition at the level of related data, which contains functionality oriented to the practical and accessible use. On the other hand, this database, compared to the others, performs functions efficiently with greater speed [23]. In addition, its main features are based on reliability, better performance, better accessibility and stability by being consistent [24].

\section{Software Architecture}

For the implementation of the mobile application, the software architecture was determined on the pattern of layers. These layers have a horizontal structure. In this case, it is composed of 4 layers, each of them has a specific function with responsibility for the operation of the application. For this application it was oriented to closed layers, so each one works individually but intertwined to meet the needs of the application at a general level. The first layer is the presentation layer, whose primary function is to display the information through a particular format. Likewise, layer two is the business layer, which has the functionality to perform logical functions on the business and send the information to the presentation layer. On the other hand, layer three is the persistence layer or components for data access, this layer has the functionality of being the intermediary that allows access to the information in the database and directs it to the business layer. Finally, the database layer was placed, which does not generate any movement, only to generate the requested query. In addition to the layers mentioned above, the security layer and the service agents were implemented as shown in Fig. 11.

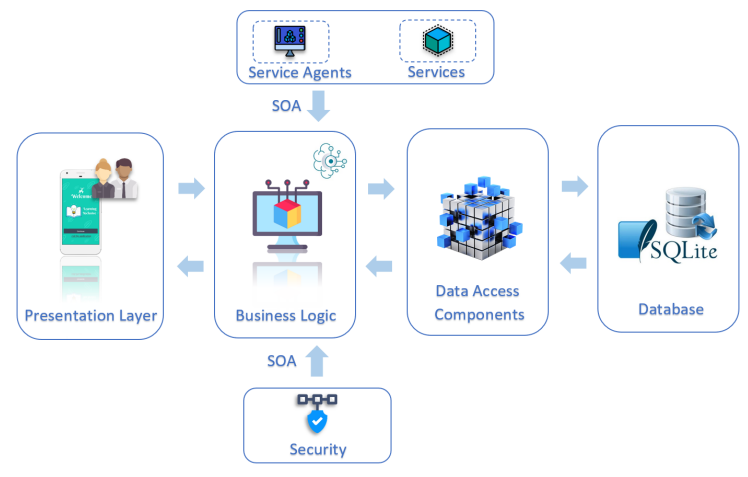

Fig. 11. Software Architecture.

\section{E. Flow Diagram}

In order to present the operation of the system on the mobile application, a flowchart is shown in Fig. 12, which details the activities step by step that can be developed within all the implemented prototypes, such as the selection of the gender of the voice assistant, the selection of the type of exam together with its level of difficulty and the course in which the exam will be taken, among other functions.

\section{RESUlTS}

\section{A. About the Methodology}

We implemented the scrum methodology for this research work, and there were found different results about it. Both good characteristics and those that could harm the development of the project. That is why it was determined to separate these characteristics for the reason that the impact they can cause depends on their knowledge and management. Therefore, they were separated into advantages and disadvantages as shown in the Table IV. In spite of this, the Scrum methodology was continued for the reason that it is adequate for this research project, reducing risks, as well as avoiding loss of resources due to the fact that it is a methodology prepared to change and to maximize the results in the face of the requirements or needs of the project.

TABLE IV. SCRUM FEATURES

\begin{tabular}{l|l} 
Advantages & Disadvantages \\
\hline $\begin{array}{l}\text { It provides quantifiable objectives, } \\
\text { which generates anticipated results. }\end{array}$ & $\begin{array}{l}\text { When one task is not completed, an- } \\
\text { other task cannot be started, which } \\
\text { causes the other tasks to be post- } \\
\text { poned. }\end{array}$ \\
\hline $\begin{array}{l}\text { The outcome and effort of the } \\
\text { project are measured in the form of } \\
\text { objectives and requirements. }\end{array}$ & $\begin{array}{l}\text { It is required that the processes and } \\
\text { their tasks go through an exhaustive } \\
\text { definition. }\end{array}$ \\
\hline $\begin{array}{l}\text { Since it is divided into short periods, } \\
\text { its verification tests are quick, which } \\
\text { means that the detailed progress per } \\
\text { sprint is known. }\end{array}$ & $\begin{array}{l}\text { It is required that the team be made } \\
\text { up of highly qualified and trained } \\
\text { people. }\end{array}$ \\
\hline $\begin{array}{l}\text { Risks can be mitigated in advance } \\
\text { without generating delays or loss of } \\
\text { resources. }\end{array}$ & $\begin{array}{l}\text { the team must have knowledge of } \\
\text { the scrum process structure in detail. }\end{array}$ \\
\hline $\begin{array}{l}\text { Being a collaborative work and } \\
\text { with a growth it is possible to in- } \\
\text { crease the level of satisfaction of the } \\
\text { project in terms of productivity and } \\
\text { quality. }\end{array}$ & $\begin{array}{l}\text { Constant meetings can generate } \\
\text { stress to the development team, so it } \\
\text { is necessary to prepare in advance. }\end{array}$ \\
\hline
\end{tabular}

- Methodological Comparison

Before the end of the results and discussions stage, a comparison of the methodology implemented in this research work with the RUP methodology, which was one of the possible options to implement, but the selected methodology was Scrum, and what are the differences between them, which can be seen in Table V.

\section{B. Sprint Analysis}

On the other hand, we analyzed the course of the three sprints developed during the project with respect to an ideal fulfillment of the points of the users stories, which in total were 51 points between the three sprints. These sprints were analyzed using the Burn Down Chart diagram, each of these sprints had a duration of 2 weeks, giving a final time of one month and two weeks of development on the mobile application, without counting Sundays and using only 8 hours per day. The execution of the sprint began on August 30, 2021 and ended on September 11 of the same year. 


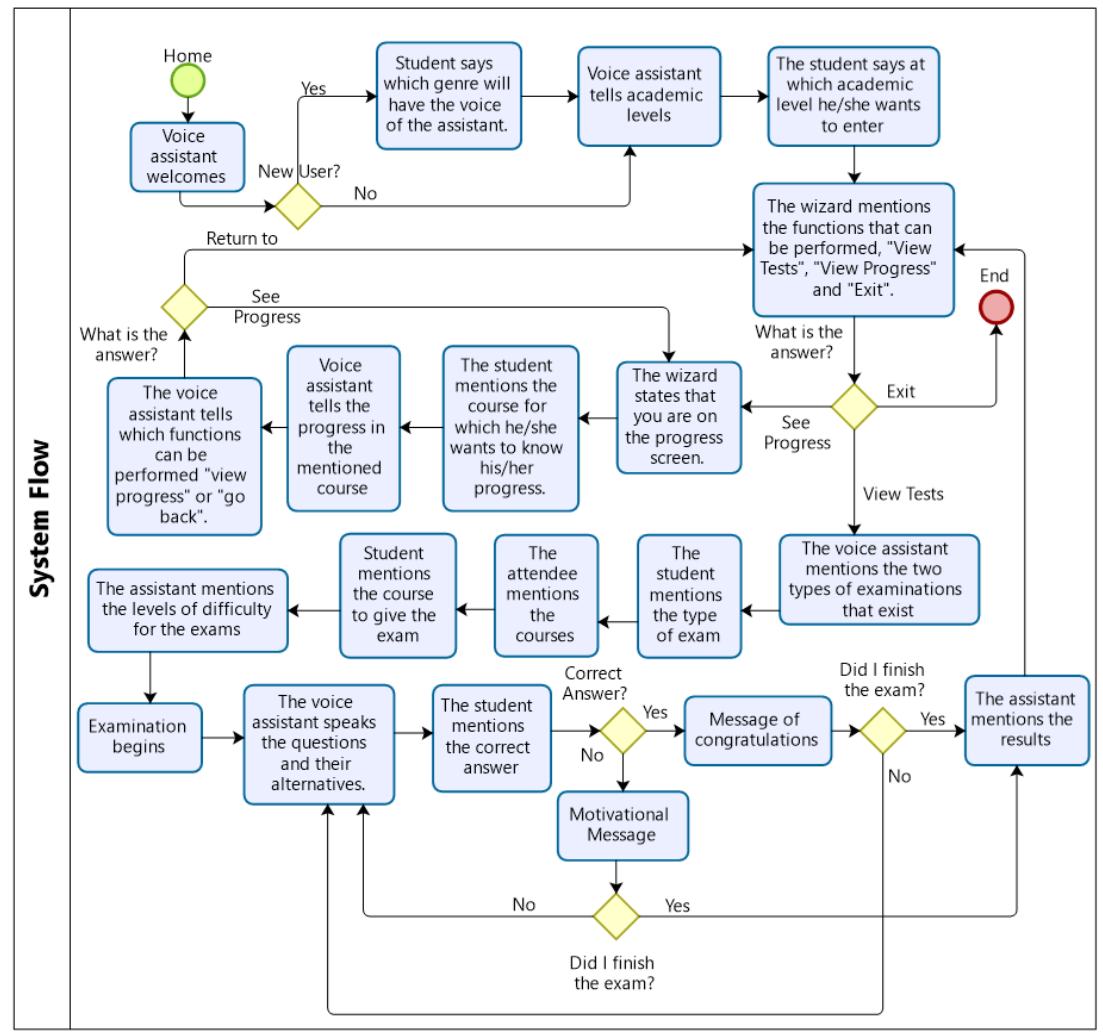

Fig. 12. Mobile System Flow Diagram.

TABLE V. DifFERENCE BETWEEN METHOdologies

\begin{tabular}{|c|c|c|}
\hline Criteria & Scrum & RUP \\
\hline Framework & $\begin{array}{l}\text { Analyze, design, imple- } \\
\text { ment and document ob- } \\
\text { ject oriented systems. }\end{array}$ & $\begin{array}{l}\text { Manage and Develop } \\
\text { incremental and iter- } \\
\text { ative process oriented } \\
\text { software. }\end{array}$ \\
\hline Review & $\begin{array}{l}\text { In each stage of the } \\
\text { methodology, one or } \\
\text { more iterations are } \\
\text { developed, with the } \\
\text { purpose of perfecting } \\
\text { the objectives, it } \\
\text { contains dependent } \\
\text { phases, if one is not } \\
\text { finished, no progress } \\
\text { can be made. }\end{array}$ & $\begin{array}{l}\text { Work carried out } \\
\text { on daily reviews } \\
\text { and risk prevention, } \\
\text { with three essential } \\
\text { questions: What did I } \\
\text { do today? What will } \\
\text { I do tomorrow? What } \\
\text { impediments did I } \\
\text { find? }\end{array}$ \\
\hline Objectives & $\begin{array}{l}\text { aims are oriented to } \\
\text { establish templates and } \\
\text { examples on the fea- } \\
\text { tures and stages of soft- } \\
\text { ware development. }\end{array}$ & $\begin{array}{l}\text { oriented to obtain an- } \\
\text { ticipated results, chang- } \\
\text { ing requirements, com- } \\
\text { petitiveness and funda- } \\
\text { mental innovation. }\end{array}$ \\
\hline Development & 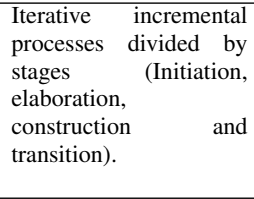 & $\begin{array}{l}\text { Oriented a simple elab- } \\
\text { oration that needs con- } \\
\text { stant work controlling } \\
\text { the project in an adap- } \\
\text { tive and empirical way } \\
\text { on the evolution of the } \\
\text { development. }\end{array}$ \\
\hline Project & $\begin{array}{l}\text { Managed for large } \\
\text { or long-term projects } \\
\text { aimed at organizations } \\
\text { with medium to highly } \\
\text { complex projects. }\end{array}$ & $\begin{array}{l}\text { Managed for companies } \\
\text { that are not dependent } \\
\text { on deadlines and are } \\
\text { looking for constant im- } \\
\text { provements. }\end{array}$ \\
\hline
\end{tabular}

- First Sprint: For the development of the first sprint, 17 story points were covered. In the diagram in Fig. 13 , the user story points were established as axis
(X) and as axis (Y) and the days in which the user stories were developed were placed, in this case from August 2 to August 14, 2021. And as a consequence it could be determined the difference between the ideal and what actually developed per day, we conclude that it didn't' t very much, allowing the established time to be met, because when the development was delayed after meeting the planned points the Scrum team complemented each other better and recovered the scope over what was planned as the ideal course.

- Second Sprint: For this Sprint, 16 user story points were formed, unlike the first Sprint, in this one there were days where the real time was ahead of the ideal time, but as in the previous Sprint, there were days where the development team could not cover what was established, which meant that the Sprint execution was completed according to the planned time, as shown in Fig. 14.

- Third Sprint: In the third Sprint, 16 users story points were defined. In the diagram in Fig. 15, the user story points can be visualized as axis (X) and as axis (Y), the days in which they were developed were placed, where they started on August 30 until September 11, 2021. Thanks to this analysis, it was observed that at this point the development team did manage to cover what was established. Likewise, there were days where the actual time was ahead of the ideal time. 


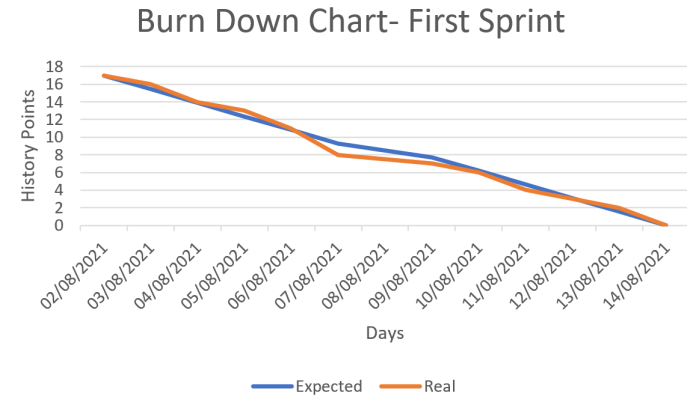

Fig. 13. Burn Down Chart - First Sprint.

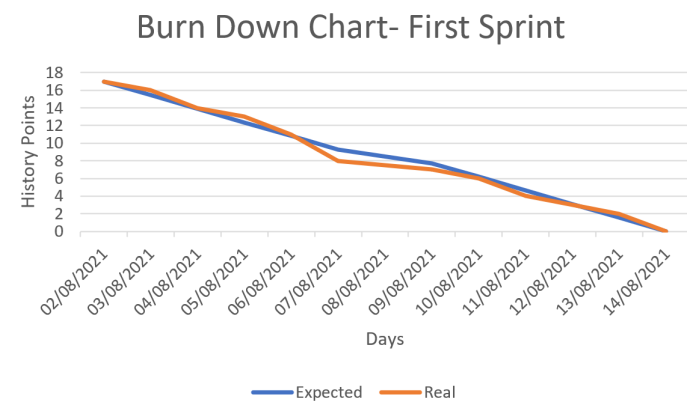

Fig. 14. Burn Down Chart - Second Sprint.

\section{About Mobile Application Satisfaction}

At this stage, a survey of 50 parents was conducted to evaluate the degree of satisfaction with the development of this mobile application for the benefit of inclusive education of blind students. Likewise, the objective of this evaluation is to know if the mobile application meets the requirements previously identified. Fig. 16 was structured by 5 options of the level of satisfaction that can be visualized in the axis (X) and as axis $(\mathrm{Y})$ the number in which the result of the percentage obtained by the survey is located was determined. Using this diagram, it was possible to determine that the objectives of this research project had a good percentage of satisfaction on the part of the users and achieved the objectives set by the authors.

\section{Discussion}

In comparison with other research works, related to the development of mobile applications and with the objective of

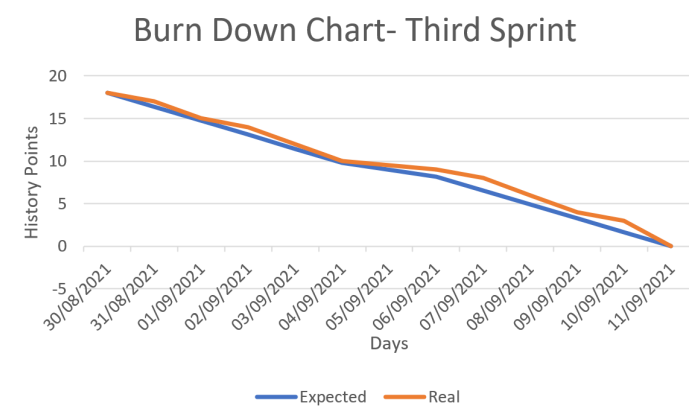

Fig. 15. Burn Down Chart - Third Sprint.

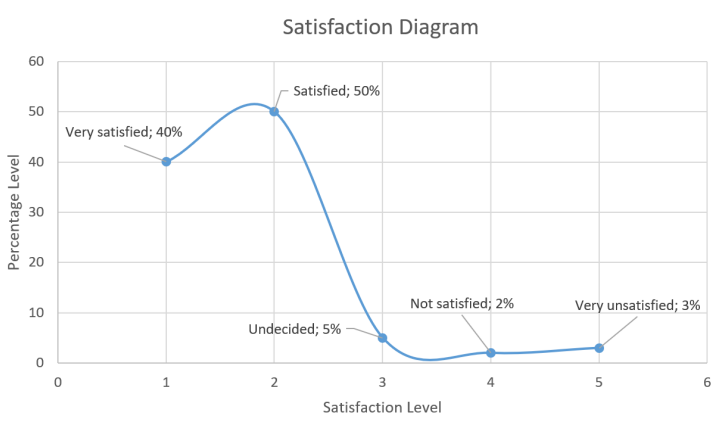

Fig. 16. Satisfaction Results.

promoting the inclusion of students who suffer from some disability that prevents them from learning development. In the article [25], it is visualized that they provide interfaces for taking evaluations, using technological methods that allow easy use. However, in this system there are interfaces that have not been designed for blind people such as login and registration, because they use text boxes where students have to fill, and not with the use of technological tools such as a virtual assistant that will guide the user to enter the application during their stay within the application, being one of the features that differentiates the application that is developed in this research work and other similar applications, as can be seen in Fig. 7(a), where there is a virtual assistant that can guide the student to enter the app and be able to develop the different activities within it. Continuing with the comparison of works, oriented in the development of educational learning mobile applications for the inclusion of students who have some impediment to be able to perform activities that usually other students can perform normally. In the article [26], it shows the design of an app aimed at children with Down syndrome disability in which, it offers writing and reading environments, where the child can learn interactively, however, this application is only aimed at a small group of students according to an age range and not with levels that the user can select and increase the level of learning, being one of the characteristics that differentiates this research work and in other similar application, as shown in Fig. 6(a), in which you can choose the level according to the user's decision. On the other hand, it does not have evaluation types such as practical evaluation and graded evaluation, being one of the features that stands out in this research work since it can benefit in academic development.

\section{CONClusion AND Future Work}

Finally, a mobile application was developed to meet the objectives required by the users, such as benefiting and promoting the educational inclusion of blind students to improve the social environment of these people. It is also concluded that the use of the Scrum methodology is one of the most appropriate ways to carry out the management of software development since the purpose of this methodology is to work together and adapt to the changes that occur within the project. The application developed within the framework of this study will bring several benefits for students with visual impairment, which can improve the quality of teaching teachers to students since it is a tool capable of eliminating the standards of society, where blind people can't grow educationally due to their dis- 
ability. Therefore, this objective was achieved. Also, as future work of this research should be taken as the beginning for a better inclusive education in Peru and in other Latin American countries, due to the fact that this type of tools can be improved by adopting new technologies for future updates as would be the case of the implementation of this mobile application with artificial intelligence and instruments for the comfort of the blind student. Finally, it is necessary to mention that with the development of this research work we want to motivate educational institutions and teachers recommending them to implement new teaching methods through these technologies so that students who have some kind of disability can reinforce their academic level inside and outside the classroom.

\section{ACKNOWLEDGMENT}

This research work was supported by the Universidad de Ciencias y Humanidades with its research institute. We also thank Dr. Sotomayor Beltran for his suggestions and recommendations in this research work.

\section{REFERENCES}

[1] V. B. Kovač and B. L. Vaala, "Educational inclusion and belonging: a conceptual analysis and implications for practice," International Journal of Inclusive Education, vol. 25, no. 10, pp. 1205-1219, 2021. [Online]. Available: https://doi.org/10.1080/13603116.2019.1603330

[2] C. Libiert and F. Nájera, "Una estructura digital accesible es un derecho humano de las personas con discapacidad visual," vol. 6, 2021.

[3] A. P. Lintangsari and I. Emaliana, "Inclusive education services for the blind: Values, roles, and challenges of university EFL teachers," International Journal of Evaluation and Research in Education, vol. 9, no. 2, pp. 439447, 2020.

[4] E. Asamoah, K. Ofori-Dua, E. Cudjoe, A. Abdullah, and J. A. Nyarko, "Inclusive Education: Perception of Visually Impaired Students, Students Without Disability, and Teachers in Ghana," SAGE Open, vol. 8, no. 4, 2018.

[5] H. Miyauchi, "A systematic review on inclusive education of students with visual impairment," Education Sciences, vol. 10, no. 11, pp. 1-15, 2020.

[6] J. C. Ponce Gallegos, B. A. Toscano, A. Silva Sprock, J. Muñoz Arteaga, and N. Aguas, "Educational inclusion in higher education: Mexico," Proceedings - 14th Latin American Conference on Learning Technologies, LACLO 2019, pp. 204-211, 2019.

[7] L. O. Topin, R. Barwaldt, L. M. I. Ribeiro, D. Spidola, A. L. C. D. Freitas, M. Pias, M. Torres, and J. Sartori, "Towards Machine Learning for Enhanced Maths Teaching to the Blind," Proceedings - Frontiers in Education Conference, FIE, vol. 2019-Octob, 2019.

[8] L. Chen, P. Chen, and Z. Lin, "Artificial intelligence in education: A review," IEEE Access, vol. 8, pp. 75264 $75278,2020$.

[9] E. G. De Oliveira, M. S. F. De Oliveira, N. R. Neto, F. De Paula Soldati, and T. L. C. Nassur, "Development and evaluation of a mobile educational application to support teaching of management of process in Operating Systems," Proceedings - IEEE 20th International Conference on Advanced Learning Technologies, ICALT 2020, pp. 19-21, 2020.
[10] M. N. Islam, T. T. Inan, N. T. Promi, and S. Z. Diya, "Information and Communication Technologies for Humanitarian Services," Information and Communication Technologies for Humanitarian Services, no. April 2021, 2020.

[11] B. K. Balasuriya, N. P. Lokuhettiarachchi, A. R. Ranasinghe, K. D. Shiwantha, and C. Jayawardena, "Learning platform for visually impaired children through artificial intelligence and computer vision," International Conference on Software, Knowledge Information, Industrial Management and Applications, SKIMA, vol. 2017Decem, pp. 1-7, 2018.

[12] Z. Masood, R. Hoda, and K. Blincoe, "Real World Scrum A Grounded Theory of Variations in Practice," IEEE Transactions on Software Engineering, vol. 5589, no. c, pp. 1-1, 2020.

[13] S. Chantit and I. Essebaa, "Towards an automatic modelbased scrum methodology," Procedia Computer Science, vol. 184, pp. 797-802, 2021. [Online]. Available: https://doi.org/10.1016/j.procs.2021.03.099

[14] V. Gomero-Fanny, A. R. Bengy, and L. AndradeArenas, "Prototype of web system for organizations dedicated to e-commerce under the scrum methodology," International Journal of Advanced Computer Science and Applications, vol. 12, no. 1, 2021. [Online]. Available: http://dx.doi.org/10.14569/IJACSA.2021.0120152

[15] A. F. Acosta, J. E. Espinosa, and J. Espinosa, "Application of the SCRUM Software Methodology for Extending Simulation of Urban MObility (SUMO) Tools," pp. 3-15, 2019.

[16] I. Khokhlov and L. Reznik, "Android system security evaluation," CCNC 2018 - 2018 15th IEEE Annual Consumer Communications and Networking Conference, vol. 2018-January, pp. 1-2, 2018.

[17] A. Sarkar, A. Goyal, D. Hicks, D. Sarkar, and S. Hazra, "Android Application Development: A Brief Overview of Android Platforms and Evolution of Security Systems," Proceedings of the 3rd International Conference on ISMAC IoT in Social, Mobile, Analytics and Cloud, ISMAC 2019, pp. 73-79, 2019.

[18] M. A. Amasha, M. F. Areed, D. Khairy, S. M. Atawy, S. Alkhalaf, and R. A. Abougalala, "Development of a Java-based Mobile application for mathematics learning," Education and Information Technologies, vol. 26, no. 1, pp. 945-964, 2021.

[19] N. Meng, S. Nagy, D. D. Yao, W. Zhuang, and G. A. Argoty, "Secure coding practices in Java," pp. 372-383, 2018.

[20] S. Liu, "Explore Java Language and Android Mobile Software Development," vol. 3, no. 2, pp. 5-9, 2021.

[21] R. O. Nia, "Komparasi Perangkat High-Fidelity Prototyping Untuk Aplikasi Bergerak Augmented Reality ( Studi Kasus : Marvel dan Proto . io ),” p. 88, 2018.

[22] A. A. Permana, R. Taufiq, and S. Ramadhina, "Prototype design of mobile application 'hydrolite' for hydroponics marketplace," in 2020 7th International Conference on Electrical Engineering, Computer Sciences and Informatics (EECSI), 2020, pp. 45-48.

[23] Z. Shen, Y. Shi, Z. Shao, and Y. Guan, "An Efficient LSM-Tree-Based SQLite-Like Database Engine for Mobile Devices," IEEE Transactions on Computer-Aided 
Design of Integrated Circuits and Systems, vol. 38, no. 9, pp. 1635-1647, 2019.

[24] Y. Wang, Y. Shen, C. Su, J. Ma, L. Liu, and X. Dong, "CryptSQLite: SQLite with High Data Security," IEEE Transactions on Computers, vol. 69, no. 5, pp. 666-678, 2020.

[25] A. Carrion-Silva, C. Diaz-Nunez, and L. AndradeArenas, "Admission Exam Web Application Prototype for Blind People at the University of Sciences and $\mathrm{Hu}$ - manities," International Journal of Advanced Computer Science and Applications, vol. 11, no. 12, pp. 377-382, 2020.

[26] R. Arias-Marreros, K. Nalvarte-Dionisio, and L. Andrade-Arenas, "Design of a Mobile Application for the Learning of People with Down Syndrome through Interactive Games," International Journal of Advanced Computer Science and Applications, vol. 11, no. 11, pp. 715-721, 2020. 